\title{
Acoustic Conditions in NICUs: Influence on Neonatal Outcome in very Preterm Neonates?
}

\author{
Akustische Gegebenheiten auf neonatalen Intensivstationen: Einfluss auf die \\ Behandlungsresultate sehr unreifer Frühgeborener?
}

Ludwig Gortner

Bibliography

DOI http://dx.doi.org/

$10.1055 / \mathrm{s}-0035-1559766$

Klin Padiatr 2015; 227: 249-250

(c) Georg Thieme Verlag KG

Stuttgart · New York

ISSN 0300-8630

Correspondence

Prof. Dr. Ludwig Gortner

Clinics for Paediatrics and Adolescent Medicine

University Hospital of the

Saarland

Building 9

66421 Homburg/Germany

ludwig.gortner@uks.eu
Survival rates in extremely low birth weight infants have been increasing during the past decades; however, this apparent progress is actually slowing $[7,14]$. A major goal of neonatal intensive care is - apart from improving survival rate, especially in the most immature infants-to improve neurologic outcome on long-term. Thus, numerous attempts have been made in the past in order to improve long-term outcome. These trials were primary focused on reduction of neurologic devastating complications, such as intraventricular hemorrhage, periventricular leukomalacia, and sepsis, respectively necrotizing enterocolitis [15].

Recent studies from epidemiologic cohorts indicate that unfavorable surrounding conditions during pregnancy, among others noise and air pollution, may increase the risk for preterm birth [5]. Noise exposure following birth in the neonatal intensive care units (NICU) in very preterm infants has been associated with various autonomic responses, among others effects on the cardiovascular system, respiration and sleep patterns [16]. It has been demonstrated that fetal heart rate and blood pressure are influenced by noise exposure in the NICU. Different hemodynamic responses however at various postnatal periods have to be demonstrated, making the problem still more complex. Fluctuations in blood pressure and heart rate may have effects on cerebral perfusion, and as a consequence, rendering the very preterm infants more susceptible to cerebral damage including brain hemorrhage and periventricular leukomalacia. A consequence standards for surrounding conditions in NICUs have been defined in order to define thresholds for light and noise exposure [9]. Furthermore, as early as in the $70 \mathrm{~s}$ of the last century, it has been proposed that physiologic auditory stimuli may improve growth characteristics of preterm neonates; thus again, the leitmotiv of the studies was improving outcome by improving local conditions in NICUs [8]. From these early studies, a number of clinical trials, which however in part were not well controlled, assessed the problem of noise reduction in the NICU as well as improving physiological acoustic conditions of very preterm neonates cared for in the NICU. Part of the trials included the NIDCAP concept of neonatal care (Newborn Individualized Developmental Care and Assessment Program) including among others improvements in acoustic conditions [17]. How- ever, meta-analyses of randomized trials were unable to confirm an improvement of long-term neurodevelopmental outcome after NIDCAP care including noise reduction [12]. A recently published meta-analysis of noise reduction as a single intervention in NICU did not show any benefits relevant effects from noise reduction on a long-term neurodevelopmental outcome variables [1]. However, due to methodological problems in many studies, this meta-analysis did include only one study enrolling only 34 neonates, who were treated with ear plaques and compared with matched very preterm neonates without ear plaques. No clear-cut superiority of reduction of noise levels from this project could be demonstrated. Thus, as the major conclusion, the authors of the meta-analysis ask for larger well controlled clinical trials in this field [1].

As there is a paucity of clinical data despite good evidence from experimental studies demonstrating detrimental effects of excessive noise exposure on cerebral function, studies as done by the Tübingen group [2] are highly necessary in order to further improve outcome by generating valid data in this field. The rational for the present study is the finding that abnormal patterns of auditory brain stem reactions have been associated with hypoxia due to bradycardia/apnea secondary to noise exposure $[6,11]$. Thus, the authors conducted a randomized controlled clinical study in order to compare the rate of bradycardia and apnea depending on acoustic conditions in very preterm neonates [2]. In line with the data from the above-mentioned meta-analysis, again no effect of noise reduction could be demonstrated in the present study: No effect of earmuffs on the rate of oxygen desaturations below $80 \%$ and bradycardia below 80 beats per minute could be demonstrated after the intervention in 31 very preterm neonates with a mean gestational age of 31 weeks and a corresponding birth weight of $1300 \mathrm{~g}$. However, the present data should be interpreted with some caution: There was a crossover design, which may not be as robust as randomized controlled clinical trials and the number of enrolled infants was low.

On the other hand, the data of the Tübingen group are in line with a recently published controlled clinical trial, in which alterations in brain structure and neurodevelopmental outcome were studied in 136 preterm infants below 30 weeks of gestational age. Study infants were ran- 
domized either to a bed space in an open ward and compared with a private room care including noise reduction within the same hospital under otherwise identical conditions of treatment [13]. In this study, even a trend for lower motor and lower language scores at the age of 2 years could be demonstrated for those neonates cared for in private rooms, i.e. under conditions among others of noise reduction. Measurements of neonatal outcomes were performed by using Bayley scales in this study. Bayley as well as Griffiths scales have been questioned at least in part with respect to their predictive value for neurodevelopmental outcome [3]. Thus, apart from well-defined interventions with respect to the optimum acoustic conditions in NICUs during the acute postnatal period in very preterm neonates, we further need to optimize instruments for controlling neurodevelopmental outcome, specifically for this kind of intervention. Furthermore, studies on noise reduction need to be well controlled with respect to distribution of neonatal complications including the rate of growth retarded neonates, chorioamnionitis as main risk factors of prematurity [10]. Apart from these considerations early childhood interventions may further alter long-term outcome variables and therefore must be controlled for [4].

Given the fact that in animal experiments and observational clinical trials effects of acoustic conditions on the acute behavior and long-term outcome have been described [16], the need for these trials is further underlined. As one part in a larger bundle of attempts to improve long-term outcome in very preterm neonates the optimal settings of acoustic conditions need to be addressed in adequately designed and powered controlled clinical trials in order to further improve long-term outcome in very preterm neonates at risk.

\section{References}

1 Almadhoob A, Ohlsson A. Sound reduction management in the neonatal intensive care unit for preterm or very low birth weight infants. Cochrane Database Syst Rev 2015; 1: Cd010333

2 Bott TS, Urschitz MS, Poets C et al. A randomized controlled trial on the effect of earmuffs on intermittent hypoxia and bradycardia in preterm infants. Klin Padiatr 2015; 227: 269-273

3 Chaudhary T, Walch E, Herold B et al. Predictive and concurrent validity of standardized neurodevelopmental examinations by the Griffiths scales and Bayley scales of infant development II. Klin Padiatr 2013; 225: 8-12

4 Clauss D, Deutsch J, Krol I et al. Early childhood intervention-access to risk families and support through actors from the health-care sector. Klin Padiatr 2014; 226: 243-247

5 Gehring $U$, Tamburic L, Sbihi $H$ et al. Impact of noise and air pollution on pregnancy outcomes. Epidemiology 2014; 25: 351-358

6 Johnson AN. Neonatal response to control of noise inside the incubator. Pediatr Nurs 2001; 27: 600-605

7 Klebermass-Schrehof $K$, Wald $M$, Schwindt J et al. Less invasive surfactant administration in extremely preterm infants: impact on mortality and morbidity. Neonatology 2013; 103: 252-258

8 Kramer LI, Pierpont ME. Rocking waterbeds and auditory stimuli to enhance growth of preterm infants. Preliminary report. J Pediatr 1976; 88: 297-299

9 Lasky RE, Williams AL. Noise and light exposures for extremely low birth weight newborns during their stay in the neonatal intensive care unit. Pediatrics 2009; 123: 540-546

10 Lindner $U$, Tutdibi E, Binot $S$ et al. Levels of cytokines in umbilical cord blood in small for gestational age preterm infants. Klin Padiatr 2013; 225: 70-74

11 Long JG, Lucey JF, Philip AG. Noise and hypoxemia in the intensive care nursery. Pediatrics 1980; 65: 143-145

12 Ohlsson A, Jacobs SE. NIDCAP: a systematic review and meta-analyses of randomized controlled trials. Pediatrics 2013; 131: e881-e893

13 Pineda RG, Neil J, Dierker $D$ et al. Alterations in brain structure and neurodevelopmental outcome in preterm infants hospitalized in different neonatal intensive care unit environments. J Pediatr 2014; 164 : 52-60 e52

14 Ruegger C, Hegglin M, Adams $M$ et al. Population based trends in mortality, morbidity and treatment for very preterm- and very low birth weight infants over 12 years. BMC Pediatr 2012; 12: 17

15 Vohr BR. Neurodevelopmental outcomes of extremely preterm infants. Clin Perinatol 2014; 41: 241-255

16 Wachman EM, Lahav A. The effects of noise on preterm infants in the NICU. Archives of disease in childhood Fetal and neonatal edition 2011; 96: F305-F309

17 Westrup B. Newborn Individualized Developmental Care and Assessment Program (NIDCAP)-family-centered developmentally supportive care. Early Hum Dev 2007; 83: 443-449 